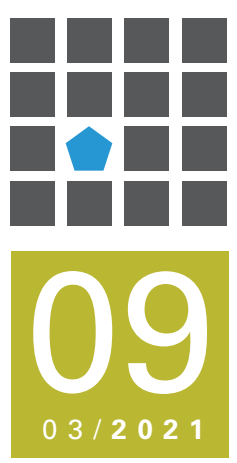

MONOGRÁFICO

Didáctica de la geografía y ciudadanía sostenible

\title{
DIDÁCTICA DE LA GEOGRAFÍA Y CIUDADANÍA SOSTENIBLE
}

\author{
Rafael DE MIGUEL GONZÁLEZ \\ Universidad de Zaragoza y EUROGEO \\ rafaelmg@unizar.es
}

La Geografía es una asignatura escolar y una disciplina científica que estudia la superficie de la Tierra, los espacios y lugares donde ocurren las relaciones entre las personas y el medio ambiente. La Geografía explora las interacciones entre el entorno físico y las sociedades humanas que se derivan en paisajes, distribuciones, impactos y patrones espaciales, desde la escala local y regional hasta la nacional y global. La geografía es la ciencia del «dónde» y sirve de guía en el proceso de indagación para entender cómo y por qué el lugar, el espacio y el medio ambiente son importantes para la vida personal y para las relaciones sociales. La geografía, especialmente en su etapa escolar, contribuye a crear conciencia sobre la diversidad humana y cultural de la Tierra. La Geografía estudia la localización de los fenómenos físicos, humanos, sociales y culturales, pero también cómo se desarrollan y cambian con el tiempo los patrones de localización. Así, la Geografía es una disciplina científica que se ocupa de la enseñanza y el aprendizaje de los procesos de organización espacial de las sociedades humanas. Por eso, la Geografía es capaz de enfrentar la complejidad y diversidad de procesos, sistemas e interconexiones entre los entornos humanos y naturales mediante el desarrollo del pensamiento analítico (datos, visualización), el pensamiento crítico (juicio, evaluación) y el pensamiento lateral (creativo, resolución de problemas).

Si la Historia es la ciencia del tiempo social y la didáctica de la historia se fundamenta en la enseñanza del tiempo histórico, la geografía lo es del espacio, y la didáctica de la geografía se articula en torno a la adquisición del pensamiento espacial y geográfico en los alumnos. El espacio geográfico es, ante todo, relacional, algo que hemos padecido todos últimamente en estos tiempos de pandemia global, en los que las limitaciones a las relaciones sociales han sido, ante todo, restricciones espaciales, de movimiento, de circulación y de interacción física. Este enfoque relacional es el que proporciona a la didáctica de la geografía un valor especial en educación para 
la ciudadanía, en un mundo físico, social y virtual que está cambiando a una gran velocidad. No podemos adivinar el futuro, pero desde la educación en ciencias sociales, sí que podemos enseñar a nuestros alumnos a prepararse mejor para su transición a una vida adulta, a unas responsabilidades individuales y colectivas ante un contexto cambiante, incierto y global.

La didáctica de la geografía, como parte de la didáctica de las ciencias sociales, cumple un papel esencial en la educación para la ciudadanía, sea en la escala geográfica que sea -ciudadanía global, ciudadanía europea o ciudadanía democrática nacional, en nuestro caso ciudadanía española-, esto es, en la adquisición de los valores supremos que, como individuos, nos permiten formar parte de la sociedad y participar en ella: derechos humanos, libertad, democracia, respeto, convivencia, etc. Y lo cumple por esa dimensión relacional entre los condicionantes físicos, los sistemas económicos, los procesos sociales, los valores culturales y la organización política de los Estados, especialmente en el mundo actual, en el que la tecnología y la globalización hacen a las sociedades más interdependientes unas de otras. En otras palabras, más relacionadas, pero también más complejas.

Por eso, en la enseñanza de los grandes retos del siglo veintiuno, resulta indispensable entender ese carácter transversal, interdisciplinar y relacional parecido que tienen la Geografía y los Objetivos para el Desarrollo Sostenible de la Organización de Naciones Unidas, que son válidos tanto para las grandes potencias mundiales como Estados Unidos y China, como para los países africanos cuya renta per cápita es inferior a 1.000 dólares por persona y año. Después del año 2030, probablemente la Agenda cambiará de nombre y alguno de los objetivos se redefinirá, pero las grandes cuestiones a las que se enfrente la humanidad, que deberemos enseñar en educación primaria y secundaria, seguirán siendo las mismas: el progreso económico, el desarrollo social, la identidad cultural, el avance tecnológico, pero sobre todo el valor de la igualdad entre los seres humanos y de la dignidad humana, garantizadas por la democracia liberal más que por cualquier otro régimen. Aquí la Didáctica de la Historia es imprescindible, enseñando cómo el fracaso de las democracias liberales en los años treinta del siglo veinte conllevó a la Segunda Guerra Mundial, así como a las dictaduras totalitarias que perduraron durante las décadas posteriores de la Guerra Fría.

No obstante, la educación para la ciudadanía no debería estar centrada sólo en la ideología, en la economía o en la tecnología, ya que depende cada vez más de la Geografía y la Ecología. El desarrollo sostenible tiene que ser económico, político y social, pero sólo si el medio geográfico lo permite, y a una escala geográfica global. Por eso, en una educación para la ciudadanía plena importan temas tan importantes como el cambio climático, el impacto sobre los océanos y el fitoplancton, la deforestación (por ser bosques y océanos los productores del oxígeno que respiramos), el agua, la alimentación, las ciudades, etc. La educación geográfica debe proporcionar al alumno conocimientos y rigor científico en la obtención y tratamiento de los datos, para que los valores ciudadanos estén fundamentados en hechos contrastados, no en informaciones puntuales, efímeras y en ocasiones manipuladas.

En definitiva, la educación geográfica es un elemento básico de la educación para la ciudadanía y para la educación para el desarrollo sostenible. Y no solo porque los grandes temas de ambas lleven siendo objeto de estudio durante décadas de la ciencia geográfica (geografía política, 
geografía social, geografía física, geografía regional), sino porque permite al alumno ser más autónomo en su percepción del mundo físico y social, y también en su interacción con él.

Estas cuestiones son las que impregnan el conjunto de las contribuciones de este número monográfico de Didacticae sobre Didáctica de la Geografía y ciudadanía sostenible, como el artículo de Mario Corrales y Jacinto Garrido en donde plantean una experiencia de gamificación para integrar los Objetivos para el Desarrollo Sostenible en el currículo de Geografía e Historia de $1^{\circ}$ de la ESO, o como el trabajo de Daniel Llancavil sobre la educación geográfica en Chile.

Pero educar en ciudadanía sostenible no es una tarea sencilla, ya que es una dimensión relativamente nueva a la que el profesorado debe hacer frente. Francisco García Pérez analiza sus dificultades como la reflexión epistemológica, los libros de texto o la cultura escolar, frente a las que se plantea una alternativa basada en la investigación escolar basada en problemas: investigación del medio, cuestiones socialmente vivas, cuestiones candentes, temas controvertidos, problemas socioambientales, etc. José Antonio López reitera las dificultades de la enseñanza de la educación para la ciudadanía sostenible a partir de una investigación sobre las representaciones sociales, sesgos e incluso imprecisiones de los retos ambientales en el profesorado en formación. Ello no debe ser obstáculo para reforzar la formación inicial del profesorado en ciudadanía sostenible, como explican Rosa Medir y Anna Serra en su artículo que presenta una experiencia centrada principalmente en los ODS de carácter social. Si existen dificultades por parte del profesorado, no son menores en los alumnos al abordar temas de cierta complejidad conceptual, y mucho menos en alumnos con necesidades educativas especiales. Oscar Jerez y Claudia Vera detallan en su contribución a este número su diseño de un programa de Educación Ambiental para estudiantes con Trastorno del Espectro Autista (TEA).

Como puede comprobarse, este número de didáctica de la geografía y ciudadanía sostenible incluye los grandes temas clásicos de la investigación en didáctica -formación del profesorado, dificultades de aprendizaje en el alumnado, currículo, materiales didácticos, diseño instruccionalreferidos a una temática clásica -las relaciones de los grupos sociales, entre sí y con el medio en que habitan-, aunque renovada por la creciente interdependencia global, de manera que la agenda política, social y educativa ha puesto el foco en la enseñanza de la geografía como medio para comprender mejor la sostenibilidad del mundo en el que van a vivir los niños y jóvenes que hoy en día se están educando. 